\title{
Adapting to climate change: an evolving research programme
}

Article

Accepted Version

Arnell, N. W. (2010) Adapting to climate change: an evolving research programme. Climatic Change, 100 (1). pp. 107-111. ISSN 0165-0009 doi: https://doi.org/10.1007/s10584-0109839-0 Available at https://centaur.reading.ac.uk/16342/

It is advisable to refer to the publisher's version if you intend to cite from the work. See Guidance on citing.

To link to this article DOI: http://dx.doi.org/10.1007/s10584-010-9839-0

Publisher: Springer

Publisher statement: The original publication is available at www.springerlink.com

All outputs in CentAUR are protected by Intellectual Property Rights law, including copyright law. Copyright and IPR is retained by the creators or other copyright holders. Terms and conditions for use of this material are defined in the End User Agreement.

\section{www.reading.ac.uk/centaur}

\section{CentAUR}

Central Archive at the University of Reading

Reading's research outputs online 


\title{
Adapting to climate change: an evolving research programme
}

\author{
Nigel W. Arnell \\ Walker Institute for Climate System Research \\ University of Reading \\ UK \\ n.w.arnell@ reading.ac.uk
}

\section{Introduction}

Since its launch in 1977, the scientific issues addressed by papers published in Climatic Change have changed considerably. Nuclear winter came and went, and papers have come from an increasingly diverse range of disciplines. Most obvious, of course, has been the emergence to overwhelming dominance of papers concerned with the processes and consequences associated with the climate changes driven by increasing human emissions of greenhouse gases. Within this theme too, it is possible to track the evolution of different topics over the last thirty years. In the pages of Climatic Change, as within the climate change research community, increased attention has been given to adaptation to a changing climate. Here, I examine the scale and characteristics of adaptation research in Climatic Change, draw some general conclusions from the research published in Climatic Change, and suggest from this some future research directions.

\section{A quantitative analysis}

Between volume 1 in 1977 and volume 99 (1-2) in 2010, over 2400 papers $^{1}$ have been published in Climatic Change. A key word search for "adaptation", supplemented by visual inspection for volumes prior to 1992 for which abstracts are not searchable online, identifies around 180 papers which at least refer to adaptation ${ }^{2}$. Figure 1 shows the number of papers on adaptation over time, together with the proportion of published papers concerned with adaptation ${ }^{3}$. The proportion is clearly increasing, with early peaks in 1997 and 2000; these correspond to two special issues in 1997 (one presenting results of impacts studies conducted under the US Country Studies Programme and the other focusing on climate change and water resources planning) and one in 2000 (focusing on societal adaptation to climatic variability and change).

Figure 2 gives a (rather generalised) breakdown of the "adaptation" papers within Climatic Change. One categorisation (Figure 2a) divides papers into three types. The first type focus on what could be termed "conceptual" issues around adaptation; $19 \%$ of the "adaptation papers" fall into this type. These include papers on definitions of adaptation,

\footnotetext{
${ }^{1}$ Including editorials, commentaries and corrections

2 This total may miss some relevant papers which do not explicitly mention the word "adaptation" in title, abstract or key words

${ }^{3}$ There have been step changes in the total numbers of papers published in 1991, 1996 and 2005 as the number of volumes published per year have increased
} 
the relationships between adaptation and vulnerability, the effect of uncertainty, and the development and use of decision-support tools. Some of these papers include specific examples - in particular places or sectors - but the primary aim of these papers is to present some conceptual development. The second type of papers (38\% of the total) have an explicit focus on some aspect of adaptation for a specific region or sector. Some explore the implications of certain climate impacts for adaptation strategies in a general way, and others (a minority) assess specific adaptation measures, either actual or planned. Some of the papers explore the factors affecting adaptation decisions and actions. These studies are predominantly in the food/agriculture and water resources areas (Figure 2b), with the coastal zone coming a poor third.

The third type of papers (the remaining 43\%) actually focus on impacts, and only refer to adaptation either in the context ("...in order adapt it is necessary to understand impacts..") or in a general way in the conclusions ("the implications of the results for adaptation are...”).

\section{Emerging conclusions}

In the first 99 volumes, of the order of 100 papers have therefore been published in Climatic Change which explicitly examine some aspect of adaptation (fewer than 5\% of the total papers published). From this suite of papers, we can draw three general conclusions.

- There is substantial research evidence on the potential effectiveness, or otherwise, of some specific adaptation measures and assessment techniques, particularly in the agricultural and water sectors. Many of the 100 papers give good illustrations of how particular techniques could work to reduce the impacts of climate change, and demonstrate how particular assessment methods may be applied.

- There are, however, very few published examples or case studies of how adaptation to climate change is actually being delivered, or on the barriers (of information, capacity, institutions etc) which will influence how adaptation takes place.

- Context matters. Both the case studies and the assessments of potential adaptation measures show that local circumstances - geographical characteristics, current management practices and institutional structures - significantly affect what adaptation options are considered feasible, what information is likely to be used, what assessment techniques are adopted and, crucially, how adaptation decisions are actually made. This implies that it will be difficult (i) to make generalised assessments of the potential contribution of adaptation to managing the risks posed by climate change and (ii) to construct generalised models of the adaptation process. 
There are some key gaps. First, although there are some important papers exploring adaptation from a vulnerability perspective, the adaptation papers in Climatic Change predominantly take a scenario-driven perspective, and this perhaps reflects the journal's strong foundations in the physical sciences. Second, even within this scenario-driven perspective, there have been very few papers explicitly seeking to examine how most appropriately to use climate science to inform adaptation assessments and decisions. A large number of papers have presented examples of ways of using different techniques in impact assessments - such as the use of regional climate model output, sophisticated downscaling techniques or the construction of scenarios from spatial analogues or circulation types - but the requirements for adaptation management may be rather different to the needs of impact assessments. These requirements will be shaped by the institutional context within which adaptation takes place; a key requirement is often for information over shorter time horizons than is currently provided in conventional climate impact assessments. This research gap is by no means unique to Climatic Change.

\section{A new research agenda}

So what does this review - of papers published in just one journal - imply for future research into adaptation? I propose that this should build on the existing knowledge base and be organised around three key questions. The way these questions are phrased, addressed and answered will depend on local context.

\section{How will adaptation to climate change occur?}

Research here would focus on what actually drives and constrains adaptation at a place, in a region, or by a sector. Specific research questions could include:

What makes the "adapting agent" vulnerable or exposed to a changing climate?

What influences preparedness to adapt?

What are the potential adaptation options ${ }^{5}$, and how would they work?

What are the factors which encourage or discourage the implementation of adaptation measures?

What are the consequences of the implementation of adaptation measures?

How does pressure to adapt to climate change compare with other pressures?

\section{How can effective adaptation be facilitated?}

Research in this area would involve the development of appropriate methods - which must be context specific - which would encourage "effective" adaptation. Specific research questions could include:

What is meant by effective adaptation?

\footnotetext{
${ }^{4}$ Individual, business or public organisation

${ }^{5}$ Including not only options to manage climate risks and alter exposure to loss, but also measures to increase resilience
} 
What information is needed to support adaptation decisions and actions, and how can this be produced?

What are the advantages and disadvantages of different ways of representing and coping with uncertainty?

How can the costs and benefits of adaptation measures be assessed?

How can the advantages, disadvantages and implications of different adaptation measures be evaluated?

What tools and decision-making approaches will help support effective adaptation?

How can adaptation be incorporated into established and emerging decisionmaking processes?

How can adaptation to climate change be linked with other challenges - e.g. development - and with climate change mitigation?

How do institutional structures need to change to better facilitate adaptation?

(iii) How effective will adaptation be in responding to the consequences of climate change?

Research in this area would explore the extent to which adaptation addresses the challenges posed by climate change. Specific research questions include:

What proportion of impacts can be managed through adaptation - in principle and in practice - and what are the residual impacts?

Are there limits to adaptation, and what does this imply for mitigation targets and policies?

What are the relative costs, benefits and consequences of adaptation and mitigation?

To what extent does adaptation to current climatic variability cope with a changing climate?

How can adaptation be represented in simulation and assessment models?

This rather simple framework provides a structure for organising and assessing adaptation research. Some individual research activities may take a very conceptual approach, whilst others may focus on specific technical aspects of a particular adaptation option, or on ways of encouraging community resilience to climate change. Some research may take a global perspective, and some may be strongly grounded in local experience. The papers published in Climatic Change in its first 99 volumes contribute to many of these questions. A new concerted attempt to address adaptation to climate change requires inputs from many disciplines, and also an interdisciplinary perspective it is arguably at the linkages between the physical, natural and social sciences that the greatest advances will be made in understanding the complexities of adaptation and developing credible and realistic ways of facilitating adaptation to climatic change. Climatic Change is the ideal forum for such an exchange and debate. 
Figure 1: Papers on "adaptation" published in Climatic Change in volumes 1 to 99 (1-2).

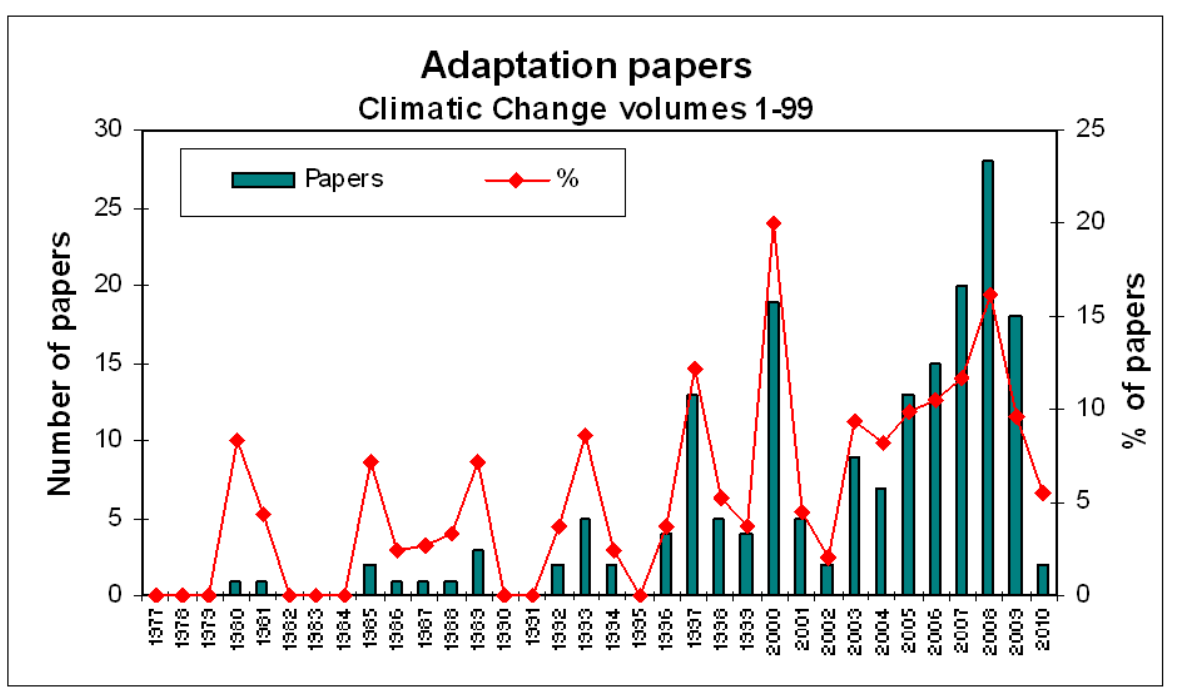

Figure 2: A categorisation of adaptation papers published in Climatic Change.

a) Overall focus of the adaptation papers

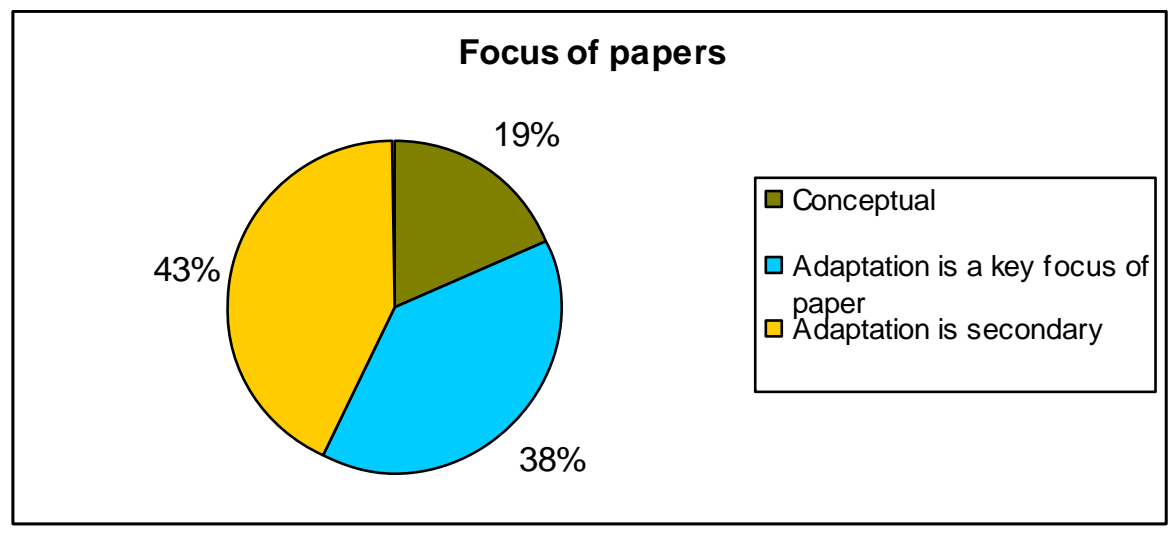

b) Sectoral classification of papers with adaptation as a key focus

\begin{tabular}{|l|l|}
\hline Sectoral classification \\
W Food and agriculture \\
$\square$ Coastal \\
$\square$ Built Environment \\
$\square$ Ecosystems
\end{tabular}

